\title{
Ricardo Piglia, lector de Witold Gombrowicz
}

\author{
Ewa Kobylecka-Piwonska
}

Published online: 14 October 2012

(C) The Author(s) 2012. This article is published with open access at Springerlink.com

\begin{abstract}
Although Gombrowicz's stay in Argentine has been the object of many meticulous investigations, the critical works dedicated to contemporary Argentinean writers' debt to the author of Ferdydurke are scarce. The article focuses on the Ricardo Piglia's interpretation of Gombrowicz, on the way in which he uses him in his own project of literary canon reorganization. According to Piglia, the Polish writer occupies the central place in Argentinean literature, being close, on one hand, to Jorge Luis Borges' understanding of the national tradition, and on the other, to Roberto Arlt's conflict rhetorics.
\end{abstract}

Keywords Gombrowicz $\cdot$ Piglia $\cdot$ Arlt $\cdot$ Borges $\cdot$ Canon

La prolongada estancia de Gombrowicz en Argentina (1939-1962) ha hecho correr mucha tinta en ambos lados del Atlántico: se ha catalogado su archivo argentino con una minuciosidad excepcional, se ha entrevistado a sus amigos y se han rastreado sus pasos (entre otros, Gombrowicz 2005; Kalicki 1984; Matamoro 1989; Abos 1991; Jarzębski 2000; Espejo 2004; Suchanow 2005; Montesano 2009). Resulta curioso, pues, constatar cómo este afán de una reconstrucción histórico-literaria contrasta con la escasez de textos dedicados a investigar el lugar de Gombrowicz en la literatura argentina contemporánea y su posible legado para con los escritores rioplatenses, los cuales, en cambio, no han dejado de exhibir su parentesco con el autor polaco. Entre los que han admitido-a veces extremando-la influencia de Gombrowicz, se cuentan Juan José Saer, César Aira, Luis Gusmán y, sobre todo, Ricardo Piglia. ${ }^{1}$ El presente artículo se dedicará a investigar las afinidades-tanto

\footnotetext{
1 Sólo he podido localizar tres estudios críticos dedicados a la relación entre Piglia y Gombrowicz: (Grzegorczyk 1996; Gasparini 2007 y Blanco Calderón 2008).
}

E. Kobylecka-Piwonska $(\bowtie)$

Departamento de Filología Española, Universidad de Lodz, Lodz, Poland

e-mail: ewapiwonska@ymail.com 
evidentes, como forzadas por el que busca "crear a sus precursores" - entre el autor de Respiración artificial y el escritor polaco. Sería quizás más legítimo hablar de "estrategias de uso" que de "afinidades", ya que Piglia no suele acatar las directrices interpretativas de las que Gombrowicz abastecía generosamente a sus lectores, sino proponer "lecturas desviadas", alejadas del contexto polaco, cruzadas con otros autores cuyos nombres-al menos en el marco de la "gombrowiczología" - raras veces se mencionan junto con el del autor de Ferdydurke. No hay que olvidar que el fin último de las lecturas gombrowiczianas que propone Piglia es encontrarle su lugar en la literatura argentina, dar con las coordenadas que le ubicarán entre varias poéticas en plena ebullición.

Leyendo a Gombrowicz, Piglia se lo apropia, por tanto, para servirse de él en su propio proyecto crítico, que consiste en batallar por la reorganización del canon literario argentino. No es, por cierto, el único autor al que Piglia somete a una nueva lectura, ya que también la recibieron, entre otros, Roberto Arlt y Jorge Luis Borges. La posición de Gombrowicz se fijará, como veremos más adelante, en la tensión entre estas dos poéticas que se suelen percibir como antagónicas y cuyo cruce ha sido siempre "una de las grandes utopías de la literatura argentina" a partir de la cual "se arman todas las genealogías, los parentescos y las intrigas" (Fornet 2000a, 23). La decisión de asignarle al escritor polaco este lugar honorífico y central debe parecer un gesto desafiante, si se tiene en cuenta el que, durante su estancia en Argentina, Gombrowicz no hiciera más que persistir obstinadamente en la periferia, que le aseguraba la "perspectiva exterior" tan elogiada por Saer (2004). Como se verá, la actitud pendenciera del polaco hacia el mundillo literario bonaerense encuentra cabida en el proyecto pigliano, en el que se concibe la tradición literaria en términos de tensiones y luchas: la renovación del canon se lleva a cabo mediante el conflicto de poéticas, los textos se leen siempre unos contra otros (este tono beligerante es exactamente el del Diario gombrowicziano). ${ }^{2}$ Lo que es más, en el caso de un canon tan corto y pedante como el argentino, la renovación se vuelve aún más problemática, porque exige cada vez una nueva lectura de los mismos textos (Piglia 2006, 157). Esta se consigue mediante un cambio del lugar que ocupa una obra en el campo de la literatura argentina, normalmente del periférico al central, siendo este desplazamiento a menudo condicionado por la afiliación de un texto nacional con otro, extranjero. Dicho condicionamiento es siempre recíproco: obras "intrusas" determinan, es cierto, la lectura de textos nacionales, pero estos, a su vez, las incorporan siguiendo sus propias pautas de interpretación, es decir, las usan a su guisa:

La literatura nacional es la que organiza, ordena y transforma la entrada de los textos extranjeros y define la situación de lectura. Que yo diga, por ejemplo, que me interesa Brecht o William Gaddis, no significa nada; habría que ver desde dónde los leo, en qué trama incluyo sus libros, de qué modo ese

\footnotetext{
2 Empleo aquí indistintamente los términos „canon” y „tradición”, siguiendo el uso corriente de ambos. Es menester matizar que Piglia-por lo menos en algunos contextos-distingue los dos vocablos: "canon" es letra muerta, lectura escolar, institucionalizada, mientras que "tradición" es dinámica y se construye de manera espontánea y natural (Piglia 2008a, 162-163).
} 
contexto los contamina, de qué forma puede "recibir" su escritura la lengua nacional. En el fondo uno se apropia de ciertos elementos de las obras extranjeras para establecer parentescos y alianzas que son siempre una forma de aceptar o de negar tradiciones nacionales (Piglia 2006, 56).

El lugar de Gombrowicz, al ubicarse entre argentinidad y extranjería, es algo resbaladizo: por un lado, Piglia no vacila al proclamarlo "el más grande escritor argentino moderno"; por otro, tiende a exponer, como Saer, su beneficiosa condición de extranjero. La pregunta que aquí se impone es la de saber en qué medida y bajo qué condiciones Gombrowicz puede ser realmente considerado "escritor argentino". ${ }^{3}$ Piglia no la formula de manera expresa, incluso parece dar su argentinidad por sentada, hiperbolizándola en el rótulo "el más grande escritor argentino moderno", pero los mismos acercamientos a su obra hechos desde y para el contexto rioplatense proporcionan tácitamente argumentos en favor de la argentinidad de Gombrowicz más acertados que cualquier cita del Diario argentino.

Gombrowicz arriba a Buenos Aires en 1939 y toma la escandalosa decisión de quedarse al explotar la noticia sobre el estallido de la guerra: sordo a las llamadas de la patria, se resuelve a empezar de cero en un país cuya lengua ni siquiera conoce. En aquellos años, Argentina hospedaba a toda una pléyade de escritores europeos y norteamericanos: en 1929 llegaron el conde Keyserling y Waldo Frank; en 1932, Pierre Drieu la Rochelle; en 1939, José Ortega y Gasset y Roger Callios. Todos ellos, no obstante, fueron en condición de árbitros, invitados por la elite intelectual para evaluar el progreso de Argentina en su camino hacia la madurez cultural. Gombrowicz, en cambio, es uno de los miles de inmigrantes pobres que en los años 30 nadie esperaba ya con los brazos abiertos, y encima tan irritablemente proclive a la polémica, rasgo que aún le dificultaba más los ya de por sí delicados contactos con los salones literarios.

A pesar de ello_-o, mejor dicho, por ello mismo- el escritor polaco le resulta tan eficaz a Ricardo Piglia que, un tiempo después, se propone revisar las jerarquías literarias de los años 30. "En esos años se multiplican y se diferencian las instancias de consagración. Ha dejado de ser el juicio de los grandes intelectuales (como Cané, Groussac o Lugones) el que consagra a un escritor; esa valoración se construye y está ligada a grupos y a formas cada vez más orgánicas (revistas, suplementos culturales, editoriales)" (Piglia 2006, 72). En aquella época, caducado el modelo autoritario de legitimidad proclamado por Sur, el campo cultural se volvió más igualitario, variado y antagónico, lo que Gombrowicz recogió en el Diario con su sorna habitual: "es un país al revés, donde un mocoso vendedor de una revista literaria tiene más estilo que todos sus colaboradores, donde los salones-plutocráticos o intelectuales-horrorizan por su mediocridad" (2011, 111). El autor de Transatlántico protagoniza tres textos de Piglia (y en varios otros aparece como punto de referencia más o menos explícito): la novela Respiración artificial de 1980, la conferencia "La novela polaca" de 1986 y el artículo "La lengua de los desposeídos”, publicado en La Nación en 2008. En todos ellos, el lugar de Gombrowicz en las letras argentinas queda definido como paradójico, ubicándose en la periferia, pero céntrica: en el cruce entre las poéticas de Borges y Arlt.

\footnotetext{
${ }^{3}$ Esta cuestión ha sido ampliamente debatida, entre otros, por Mandolessi (2007, 2008).
} 


\section{Borges y Gombrowicz}

La lectura pigliana de Borges, como bien se sabe, se basa en la estrategia de nacionalización. Descubierto por los franceses en los años 50, el autor de Ficciones se convirtió enseguida en un escritor leído básicamente en clave universal, línea interpretativa que Piglia se propone invertir al calificar la obra borgeana como culminación de la literatura argentina del XIX. Nótese que con parecido gesto nacionalizador, Piglia "se apropia" de Gombrowicz. Contrariamente a la lectura francesa, que se proponía-teniendo para ello todas las prerrogativas necesarias-la consagración universal de ambos escritores, el proyecto pigliano tiene un alcance meramente local, exorcizando quizás de este modo la decimonónica nostalgia argentina por "ser europeos".

Leyendo a Borges, Piglia cree leer, dispersa en todas sus narraciones, una "ficción de origen" o una "reconstrucción genealógica": sea cual fuere la anécdota que se cuenta, en el fondo, se quiere hablar sobre el "legado familiar" recibido de los padres. Su propio lugar en las letras argentinas, Borges lo fija apelando a la tradición que representa la rama materna y paterna de su familia: la primera, descendiente de conquistadores y héroes nacionales, encarna el coraje, la nobleza, pero también la barbarie cultural; la segunda, de origen inglés, connota el europeísmo y la cultura. Borges, heredero de ambas, es también el que las clausura. Las secuelas de su biografía las sufre en mayor o menor medida cualquier escritor, pero en el caso de Borges y-añadámoslo enseguida-Gombrowicz, estas parecen especialmente graves: la "ficción de origen" traza los caminos de la lectura de la tradición literaria y fija su lugar frente a ella. "Empecemos por mi familia, esto tiene su importancia", le dice Gombrowicz a Dominique de Roux antes de proceder a la distinción de la herencia recibida de los padres. La línea masculina representa lo práctico-el sentido del deber, el trabajo, la cordura, pero también ciertas deficiencias de sensibilidad artística-, mientras que el legado femenino se construye exactamente al revés, aportando el don de la imaginación y una gran emotividad cercana a la hiperestesia y hasta el neurotismo. En la dialéctica de los sexos, la madre parece dominar: gracias a su legado-al que puede añadirse la locura, heredada también por la línea materna-se forma lo esencial del estilo gombrowicziano. Esta formación, no obstante, se lleva a cabo mediante la negación: la "narración de la familia" cuenta, es cierto, la historia de la herencia cultural, pero enfatizando su pernicioso peso. Si a Borges la "reconstrucción genealógica" le enraíza en un espacio familiar, en un contexto que manipula a su guisa, a Gombrowicz le sirve más bien para contar la huida de la casa, entendida tanto como su mansión en Maloszyce, como la patria. La obra del polaco va a gravitar alrededor del tema de las limitaciones impuestas por la familia (autoridad, nación, etc.), comenzando por las normas de comportamiento y terminando en la lengua y la forma literarias (Jarzębski 2000, 10-34).

Como queda dicho, uno de los textos que Piglia dedica a Gombrowicz lleva el provocativo título de "La novela polaca". Provocativo, por un lado, por el contexto: originariamente, era una intervención en un debate sobre la condición de la novela argentina [sic], llevada a cabo en un congreso celebrado en la Universidad Nacional del Litoral en 1986. Por otro, hasta una lectura muy epidérmica del texto bastaría 
para constatar que su contenido no trata sino muy de paso la cuestión de la novela polaca, ciñéndose más bien al mero lugar de Gombrowicz en las letras argentinas (de hecho, el mismo texto fue posteriormente reimpreso en la revista Espacios de crítica y producción bajo el título “¿Existe la novela argentina? De Borges a Gombrowicz"). Al principio, el autor recuerda "una escena memorable" de Transatlántico ("una de las mejores novelas escritas en este país"), un singular duelo de salón entre "Gombrowicz" y un Maestro, Gran Escritor, identificado con Eduardo Mallea o Carlos Argentino Daneri de "Aleph". Piglia, para ser preciso, no usa la tan gombrowicziana palabra "duelo", sino "payada", con lo cual hábilmente apresa al polaco en la tradición argentina, y eso que no en su culta rama europea, moderna, sino en la popular y provincial:

Despojado de su originalidad este europeo aristocrático y vanguardista se ve empujado casi sin darse cuenta al lugar de la barbarie. A partir de allí la política de "Gombrowicz" en este duelo será la táctica de la ironía salvaje y del malón hermético: actúa como uno hubiera esperado que actuaran los ranqueles en el libro de Mansilla (Piglia 2001, 71-72)

Así, Gombrowicz queda cercado en la provincia argentina, forrado de la barbarie y dispuesto a mordisquear a los eruditos como un salvaje cualquiera: el virus de Sarmiento lo contagia nada más instalarse en la tierra argentina. En esta escena, prosigue Piglia, circulan "los tonos y las intrigas de la ficción argentina. Los lenguajes extranjeros, la guerra y la pasión de las citas. Son los problemas de la inferioridad cultural los que están puestos en juego y ficcionalizados" (2001, 72). La paradoja que encarna Gombrowicz es, pues, la siguiente: un escritor europeo, pero desprovisto de autoridad literaria (de la que gozaban solo los que fueron "invitados"), se convierte en un "escritor argentino" por antonomasia, definido precisamente por su pertenencia a una cultura secundaria. Como si el rechazo por parte de la institución literaria que era Sur-por cierto obsesionada, en su momento, con definir la "argentinidad"—fuera una condición sine qua non para convertirse en un "escritor argentino". Esta misma paradoja la formuló Borges - aunque, claro está, echando mano de otros conceptosen el ensayo "El escritor argentino y la tradición", donde define la intangible "argentinidad" como una relación peculiar con las grandes tradiciones culturales. Las literaturas minoritarias, como la argentina o la polaca, se caracterizan por su uso irreverente de todo el legado literario occidental, puesto que-ubicadas en la periferia cultural—no le tienen que profesar ningún culto ferviente. En el Corán, ya se sabe, no hay camellos: el colorido local no determina la "autenticidad" de un texto y la "esencia nacional" no es dada de una vez por todas, sino que sufre un proceso de construcción permanente. "Todo lo que hagamos con felicidad los escritores argentinos pertenecerá a la tradición argentina" (Borges 2005, 273).

Este razonamiento le debe de sonar a cualquier lector de Gombrowicz que se esmeró en repetidas ocasiones en desentrañar la cuestión de la "forma" cultural polaca - o, si se quiere, la de cualquier país "secundario"-, debilitada y titubeante, cuán distinta de la firme "forma" francesa o inglesa. Ninguno de los grandes procesos culturales europeos_como el Renacimiento o la Revolución industrial— moldeó realmente estos países situados en las afueras de Occidente y cuya literatura 
es desde hace años taponada por la misma temática, sea esta la cuestión de la independencia perdida o el eterno dilema entre barbarie y civilización. Esta inmadurez cultural, al conseguir quitarse de encima la carga de su terca preocupación por lo provincial, les daría una libertad espiritual y permitiría revisar - o sea, usar irreverentemente-la rígida forma europea. Su reconsideración—o relectura —es, pues, posible solo desde posiciones periféricas, donde la misma se vuelve menos apretada y perfecta (Gombrowicz 2004, 31-45).

Así pues, Gombrowicz se revela, inesperadamente y en contra de la recíproca hostilidad de ambos, pariente literario de Borges. Con este gesto se continúa la tácita operación de incluir al polaco en el canon literario argentino, cosa nada evidente si se tiene en cuenta, por un lado, el mencionado empeño del mismo en quedarse al margen y no sustituir la patria perdida por una nueva, y por otro, la más bien escasa circulación de su obra en Argentina. El parentesco con el escritor argentino más aclamado en el mundo y al mismo tiempo "nacionalizado" - como se recordarápor Piglia, sería el paso siguiente en la conversión de Gombrowicz en "escritor argentino"- después de enfatizar su pertenencia a la cultura secundaria. Los hechos históricos, como el deliberado distanciamiento, la marginalización del polaco y la ignorancia de su obra, pierden peso bajo la imponente proximidad de ideas con el autor de Ficciones. No obstante, un Gombrowicz moldeado estrictamente a la manera borgeana sería una carga sobrante para el canon argentino, ya que correría el riesgo de reducirse a uno de los innumerables epígonos del Maestro. La productividad, es decir, la capacidad de alterar las jerarquías establecidas, más que alianzas y proximidades requiere disonancias y disposición para ser diferente. De ahí que el proceso de establecer semejanzas entre Gombrowicz y los argentinos, "leerlos ilícitamente" no se acabe con Borges, sino que necesite un eslabón más.

\section{Arlt y Gombrowicz}

El subtítulo del texto pigliano arriba analizado— “De Borges a Gombrowicz"—parece poner énfasis en el parentesco entre los dos autores, sugiriendo que en esta línea hereditaria se decide el problema de la "argentinidad". No obstante, a medida que uno se adentra en la lectura, saltan a la vista — y eso sería, tal vez, la siguiente, sin duda premeditada, incongruencia del texto- otras filiaciones, sobre todo la de Roberto Arlt.

Ambos fueron—hecho tan patente que bordea la trivialidad-excluidos por el Sur, sordo al potencial literario que se encerraba en sus respectivas obras. Los dos concurrieron, en el lapso de algunos años, a una cena en la casa de Victoria Ocampo, donde consiguieron dejar una impresión de lo más negativa. Cuando la anfitriona suspiró y dijo viendo a Arlt: "Esto se está poniendo imposible. A estas reuniones ya viene cualquiera", este se limitó a replicarle: "Y putas de dos pesos también" (Drucaroff 1998, ss. 332-333). Gombrowicz, a su vez, renuente a sumarse al refinado tono de esta "distinguida peña literaria", sólo balbuceó unas palabras irreverentes en su incipiente castellano. ${ }^{4}$ Esta circunstancia histórica no pasaría de

\footnotetext{
${ }^{4}$ Hasta donde he podido averiguar, no quedan testimonios de un encuentro entre Arlt y Gombrowicz, sin dejar de ser este totalmente posible: Arlt muere en 1942, a los tres años de la estancia del polaco en
} 
ser una graciosa anécdota, si no fuera por el uso que le dieron los dos escritores a su exclusión por el establishment, haciendo de ella el núcleo de su credo literario. Otra vez citemos a Saer, que elogia la "perspectiva exterior" del polaco, distante tanto de Argentina como de Europa: "a diferencia de otros escritores polacos, como Milosz, por ejemplo, Gombrowicz hizo de su exilio un medio de ensanchar y cultivar sus diferencias con Occidente, privilegiando la particularidad de su propia perspectiva" (2004, 23). Arlt, a su vez, excluido por su origen plebeyo, forjó sobre él los cimientos de su licencia poética: no vaciló en tergiversar los hechos para ocupar un lugar hasta entonces rehuido por los escritores argentinos. Se jactó de haber sido expulsado de la escuela, mientras que, en realidad, consiguió acabar cinco cursos, un resultado completamente aceptable para un hijo de inmigrantes. Vivió en lugares más bien humildes, pero nunca-contrariamente a lo que afirmaba-en los verdaderos enclaves de la miseria. ${ }^{5}$

Arlt se inventó una figura autorial y construyó hábilmente una contundenteaunque ficticia-historia sobre su camino hacia la literatura, en una operación que Julio Premat considera típica de los escritores rioplatenses. En Héroes sin atributos. Figuras de autor en la literatura argentina, Premat sostiene que la misma se caracteriza por su fuerte tendencia a la autoficción, inseparable del proceso de escribir, ya que el gesto creativo siempre va parejo con el gesto de "inventarse como escritor". La literatura argentina se encuentra, en este aspecto, en una situación peculiar por haber tenido un mito fundacional único: a diferencia de otras literaturas, el primer modelo de escritor, insoslayable punto de referencia literario, no es un autor canónico realmente existente (como Shakespeare, Goethe, Dante, Cervantes o Hugo), sino un autor imaginario, un personaje de autor: el payador Martín Fierro. Un escritor ficticio-y no un escritor real, José Hernández-sigue siendo, en la conciencia colectiva, el que inauguró la tradición literaria argentina, y la adhesión a ella exigirá, pues, el haberse inventado una máscara de autor. Curiosamente, sus reflexiones sobre las construcciones identitarias autoriales más convincentes en la literatura argentina, Premat las inicia con... Gombrowicz: “como pocos escritores en el siglo XX, Witold Gombrowicz se construyó un lugar propio, autónomo, en contra de los abrumadores imperativos estéticos, ideológicos y sobre todo históricos que pesaban sobre las frágiles espaldas de alguien como él, un escritor polaco desterrado en el suburbio del mundo" (2009, 9). El Diario, redactado casi entero en estos arrabales de la civilización-recuerda Premat-contribuía básicamente a este objetivo: imponerse como escritor, dotarse de una personalidad fuerte. "En este diario me gustaría comenzar a construirme abiertamente mi talento" (Gombrowicz 2011, 63). "Yo soy mi problema más importante y probablemente el único: el único de todos mis héroes que realmente me interesa. Comenzar a crearse a sí mismo y hacer de Gombrowicz un personaje, como Hamlet o Don Quijote (?!).” (Gombrowicz 2011, 170). Es obvio que estas ambiciones de

\section{Footnote 4 continued}

Argentina. Además, a finales de su vida, el autor de El juguete rabioso se dedicaba, básicamente, al teatro, siendo sus piezas representadas en el Teatro del Pueblo de Leónidas Barletta, el mismo en que, en 1940, Gombrowicz dio una charla sobre "Experiencias y problemas de una Europa menos conocida".

5 Estas u otras inexactitutes en la biografía de Arlt las rastrea Saítta (2008), Goloboff (2002) y Drucaroff (1998). 
Gombrowicz se originan en el contexto polaco-el Diario fue escrito para la revista Kultura y para provocar al lector polaco-pero por otra parte, argumenta Premat, el gesto de "invención de autor" cabe perfectamente en la dinámica literaria argentina, en la que el postulado de reorganizar la tradición, en consonancia con el de revisar la identidad autorial y revalorizar las obras periféricas, están fuertemente arraigados. Así prosigue, desde un ángulo totalmente nuevo, la construcción de la "argentinidad" profunda de Gombrowicz.

La capacidad de transformar el canon deriva, entre otros, de un uso peculiar del código lingüístico o, más precisamente, de la tortuosa relación que los escritores argentinos-por lo menos los admirados por Piglia-mantenían con su propia lengua: "la extrañeza es la marca de los dos grandes estilos que se han producido en la novela argentina del siglo XX: el de Roberto Arlt y el de Macedonio Fernández. Parecen lenguas exiliadas: suenan como el español de Gombrowicz" (Piglia 2001, 75). Las tradiciones literarias realmente fértiles (o sea, flexibles, movibles) no son las que codifican el argentino: el perfecto y difícil de imitar estilo de Borges sirve más como garantía de la corrección escolar que como herramienta para minar, desde el interior, los petrificados fósiles lingüísticos. De Arlt, para variar, se ironizaba con sorna que "hablaba el lunfardo con acento extranjero" (Piglia 2001, 74), dicho mordaz que Piglia torna en un halago: los libros de Arlt, salpicados de errores lingüísticos los podría corregir cualquiera, pero nadie sabría escribirlos. Lo mismo ocurre con el polaco de Gombrowicz: lejos de ser encarnación de pureza académica, es deformado, forzado a expresar lo que antes nunca había sido verbalizado.

¿Y cómo era el español de Gombrowicz? Aprendido en los bares de mala muerte en Retiro, donde jóvenes obreros y marineros ejercían de profesores, es una lengua de contacto con desconocidos, taimada y secreta. Es el código de la difícil iniciación cultural, herramienta de "contraeducación", "la lengua de los desposeídos" (Piglia 2008b), nada equiparable al inglés de Borges o Nabokov, cincelado a la perfección con las institutrices británicas. Sobre esta "lengua áspera" nos dice mucho la conferencia "Contra los poetas", dictada por Gombrowicz en 1947. Se trata de una "crítica al lenguaje estereotipado, cristalizado en la poesía. Una crítica a la sociabilidad implícita en esos lenguajes falsamente cultivados" (Piglia 2008b), hecha desde las posiciones de carencia e inmadurez. Piglia observa con acierto que, en aquella época corroída por la nostalgia de París, la usanza era de dar conferencias en francés, así solía hacer Victoria Ocampo o Roger Callois. Si Gombrowicz, buen hablante del francés, eligió el castellano-que entonces solo chapurreaba-, y eso que se trataba de un castellano procedente de los inciertos alrededores de Retiro, lo hizo para ostentar su cisma. En el artículo titulado "La lengua de los desposeídos", Piglia cita tan solo un fragmento de esta conferencia y-conforme a su predilección por las variantes subversivas, aptas a socavar la petrificada jerarquía de los textoses un fragmento no canónico, es decir, no incluido en la última versión, publicada en el Diario polaco ${ }^{6}$ :

\footnotetext{
6 Piglia cita una versión titulada "Contra la Poesía", publicada en la revista Ciclón de La Habana en 1955 y reeditada posteriomente en Gombrowicz 2009, 11-23.
} 
Sería más razonable de mi parte no meterme en temas drásticos porque me encuentro en desventaja. Soy un forastero totalmente desconocido, carezco de autoridad y mi castellano es un niño de pocos años que apenas sabe hablar. No puedo hacer frases potentes, ni ágiles, ni distinguidas, ni finas, pero ¿quién sabe si esta dieta obligatoria no resultará buena para la salud? A veces me gustaría mandar a todos los escritores al extranjero, fuera de su propio idioma y fuera de todo ornamento y filigrana verbales para comprobar qué quedará de ellos entonces (Piglia 2008b).

En su español—una lengua inmadura, más idónea para expresar ignorancia y carencia que elegancia, refinamiento y cortesía-, Gombrowicz hace lucir también el modo de vida, contestatario e indócil, que le tocó (o más bien, que eligió) en Buenos Aires. Lengua esotérica para Borges, pero perfectamente entendible para Arlt. Con su ya mencionada propensión a invertir clasificaciones establecidas, Piglia llega a llamar la conferencia de Gombrowicz "un gran acontecimiento, casi invisible pero extraordinario. Uno de los grandes acontecimientos de nuestra historia cultural. Un gran paso adelante en la historia de la crítica literaria" (Piglia 2008b). El castellano, una lengua con un poder de fuego muy limitado, marcha lenta y débil difusión literaria, queda incluida por Gombrowicz en el circuito cultural europeo. François Bondy-prosigue Piglia-, el primer propagador del polaco en Francia, leyó Ferdydurke en castellano e, impresionado, inició su traducción al francés. El código de una cultura inferior moldea el de una cultura superior.

La crítica del lenguaje poético formulada por Gombrowicz en 1947 tiene su equivalente en una obra de Arlt: el cuento Escritor fracasado, de 1930, asimismo clave en el proyecto pigliano de los reajustes literarios (véase Fornet 2000b, 349-350). Los dos textos-el de Gombrowicz y el de Arlt-tienen forma de diatriba y se burlan de convenciones y embustes comunes en las prácticas literarias, situándose el primero en la perspectiva del lector y el segundo, en la del autor. El escritor fracasado-narrador y protagonista del cuento arltiano-, de joven proclamado, algo prematuramente, genio, relata la historia de su impotencia creadora, arrojando luz tanto sobre su propia doblez, como sobre la hipocresía del mundillo literario circundante. Al principio, tan convencido de sus capacidades como escritor, recibe con desdén pruebas literarias de otros-cojeantes, como cree, en la forma y estilo-, para terminar adoptando cada vez nuevas poses, desde el elitismo vanguardista hasta el didactismo de la izquierda, que le sirven, a fin de cuentas, solo para ocultar su falta de talento:

A mis camaradas les anuncié que preparaba la Estética del Exigente, a base de un cocktail de cubismo, fascismo, marxismo y teología [...]. En pocas semanas popularizamos nuestros principios, los desparramamos por las mesas de café y en los cenáculos, y al cabo de un año descubrimos, de acuerdo a esas leyes de nuestra estética, unos cuantos genios anónimos. Después de darles una jabonada de modernismo y afeitarles lo poco que les quedaba de claridad y lógica, los lanzamos al éxtasis de la multitud (Arlt 1995, 31-32).

El tono irónico del texto destapa-convergiendo en este aspecto con el principal mensaje del panfleto gombrowicziano_el artificio de "nuestra sublime misa de la 
estética" donde "campan [...] soberanos, el bluff, la mentira, el esnobismo, la tontería y la falsedad", para citar "Contra los poetas" (2009, 26). Gombrowicz asimismo denuncia el estéril empeño que los escritores ponen en pulir una pose estética; tampoco ahorra críticas al público, los consumidores de esta "divina ofrenda", que fingen su deslumbramiento, inflado por el ardor del poeta, reticente a "reconocer ante los demás y ante sí mismo que su canto también lo aburre, lo molesta y lo cansa" $(2009,33)$. El objetivo del polaco no se limita a achacar el esnobismo y la falsedad al mundo literario, sino que apunta a problematizar la llamada "postura poética", la manera humana de frecuentar el arte que se deja guiar por mecanismos más complicados que una simple "admiración" o "comprensión". Igualmente—matiz aún más elocuente si se buscan filiaciones entre Gombrowicz y Arlt-escribe sobre la necesidad de conflicto en el arte:

El hombre que haya tenido contacto sólo con su propio contexto social tendrá un estilo más estrecho y torpe que el hombre que ha conocido muchas personas y de varios ambientes distintos. Lo que molesta y cansa de los poetas no es ya sólo esa religiosidad que nada contrarresta, esa estéril devoción hacia la poesía, sino también su política de avestruz ante la realidad $(2009,31)$.

Y más adelante añade: "mi arte ha crecido no tanto en contacto con personas semejantes a mí sino de la relación con el adversario" $(2009,32)$. Esta beligerancia forma parte del arriba mencionado proyecto de la autocreación, presente, sobre todo, en el Diario. Con mucho acierto se ha reflejado esta confluencia de tendencias - al conflicto y a la autoinvención —en un juego de palabras polaco entre wyznanie (confesión) y wyzwanie (desafío) (véase Rodak 2011, 446).

Queda patente que el lugar que Gombrowicz se reserva en la literatura era exactamente el mismo que se asignaba Arlt. El argentino acudía a una similar retórica de conflicto, prefiriendo, es cierto, comparaciones con el boxeo y jactándose de que sus libros tienen el impacto de un cross a la mandíbula. Solía también afirmar que solo leía a Flaubert y Dostoievski y, en la vida diaria, anteponía el trato con canallas y charlatanes al contacto con la gente decente. La literatura del futuro brota, pues, en ambientes poco favorables, siendo el enfrentamiento - con otro lenguaje, otro contexto social, con un lector tibio, indiferente a los supuestos encantos de la poesía-el que le proporciona fuerzas vitales. Es más, la red de parentescos literarios no se concibe aquí en términos de intercambio espiritual o inspiración recíproca: al no haber una instancia que pueda dictaminar, en tono magistral, sobre el valor de una obra y establecer jerarquías vigentes, cada nuevo gesto literario, imponiéndose, socava los sistemas de valores ya existentes, los absorbe y vence. Piglia concluye: "Un escritor siempre tiene enemigos, porque su obra anula y cuestiona otras poéticas" (Fornet 2000a, 27).

\section{Piglia y Gombrowicz}

Hasta aquí mis reflexiones han gravitado alrededor del lugar que ocupa Witold Gombrowicz en el tablero literario argentino, de la fijación de filiaciones o zonas de influencia, conforme a la manera en la que Piglia concibe la literatura nacional: 
como un campo de batalla. A continuación, me ocuparé directamente de la relación Gombrowicz-Piglia: ¿Cómo funciona la obra del polaco en la ficción (no la crítica) del argentino?, ${ }^{7}$ ¿a qué le sirve?, ¿influyen más los textos o la leyenda de Gombrowicz? Indagado por sus precursores, Piglia pondera sus palabras:

Habría que hacer una distinción entre los textos que uno admira y los textos que uno usa, como una manera de entender la relación de un escritor con la literatura. Por ejemplo, yo admiro muchísimo la obra de Gombrowicz y no siento que la obra de él esté ligada a mi propia producción. Está ligada, claro, a mi manera de entender la literatura y a mi manera de leer otros textos (Fornet 2000a, 21).

Piglia no usa, pues, a Gombrowicz en el sentido de que sus textos no le sirven de modelos narrativos: a la absurda cadencia de la anécdota gombrowicziana prefiere, cosa bien sabida, esquemas narrativos de obras menores, de "segunda clase", como el género detectivesco. Ahora, su admiración por el autor de Ferdydurke se debe más bien a la manera en la que este entendía y comentaba el fenómeno de la "literatura": a su perspicacia e intransigencia en la apreciación de manifestaciones y modas literarias - sobre todo la inflexible crítica de los epígonos_así como a su disposición a un enfrentamiento abierto. Afirma Piglia: "la presencia de Gombrowicz produjo un efecto muy intenso en la Argentina porque él inmediatamente captó quién era Borges y lo enfrentó" (Pellegrini et al. 2010). Es, pues, en esta dimensión, o sea, como personalidad o representante de una postura filosófica ante la vida-por así decirlo, más en su contenido que en su forma-como Gombrowicz interviene en la novela Respiración artificial. $^{8}$

Los estudios críticos sobre la novela—respaldados, es cierto, por las afirmaciones del propio autor-suelen dar por sentada la identificación del personaje de Tardewski con Gombrowicz. La primera pista es el mismo apellido que alude, sin duda, a Wlodzimierz Taworski, un emigrante polaco, amigo del escritor, quien le amparó en los primeros años de su estancia en Argentina. Además, encajan otros detalles, como el trabajo en el Banco Polaco, el gusto por el ajedrez, el diario y el carácter proclive a la polémica, que le imposibilita aterrizar cómodamente en los círculos universitarios de Buenos Aires. El apellido de Gombrowicz aflora en la novela varias veces, curiosamente siempre en un contexto poco favorable, o sea, junto con otros intelectuales instalados en Argentina, a los que esta les debe su

\footnotetext{
7 Se me podría objetar que, en el caso de Piglia, la distinción entre crítica y ficción carece de sentido. Obviamente, no pretendo negar esta evidencia, sino indicar que me dedicaré ahora al análisis de la novela Respiración artificial, donde la figura de Gombrowicz opera, por así decirlo, en autonomía, sin mediación de las poéticas de Borges o Arlt ni la necesidad de posicionarse frente a ellas.

8 Otro punto en común entre Piglia y Gombrowicz que merece la pena mencionar, aunque sea al margen de mis reflexiones, es su predilección por la forma del diario. Los dos la practican o practicaron, no tanto para dejar constancia de los hechos más memorables, sino tratándola como "laboratorio de la escritura" (Piglia 2006, 51). La gran diferencia entre ambos diarios estriba en que el de Gombrowicz fue, desde el principio, una "forma de presencia" de su autor, que la usaba para imponerse o imponer su obra a sus lectores. Piglia, en cambio, protege celosamente el contenido de su diario, afirmando con excesiva modestia que va a publicar "dos o tres novelas más para hacer posible la edición de ese diario" (Fornet 2000b, 21).
} 
marcado complejo de inferioridad. El autor de Ferdydurke aparece, pues, en la estela de Paul Groussac, Charles de Soussens y Wiliam Hudson, encarnaciones del saber universal, modelos ejemplares que "no eran más que copias fraguadas, sombras platónicas de otros modelos" (Piglia 2007, 119). Insólita compañía, teniendo en cuenta el hecho de que Piglia normalmente le asigna al polaco un lugar antitético, más cercano al que ocupaba el enfant terrible Roberto Arlt. En Respiración artificial, el Gombrowicz real se quiebra, pues, en dos: en un escritor canónico, que finalmente consigue el éxito internacional y, ex post, la estima en Argentina, y en un Tardewski ficticio, un fracasado por voluntad propia, una variante fallida de Gombrowicz.

Los acontecimientos que anteceden a la llegada de Tardewski a Argentinaespecialmente el doctorado preparado en Cambridge bajo la dirección de Wittgenstein-son ficticios, salvo, para ser precisos, la fuerza del azar que los empuja a ambos hacia un país sobre el que no saben absolutamente nada, con un desconocimiento que Tardewski no vacila en calificar, irónicamente, de un “desconocimiento erudito" (Piglia 2007, 169). Dichas "inexactitudes" en la vida del protagonista hacen pensar en otro modelo real para Tardewski, un modelo normalmente olvidado en los estudios críticos sobre la novela, a pesar de no ser difícil dar con él: el mismo personaje que ha sido "marcado por Wittgenstein" (Piglia 2007, 165). El autor de la novela tampoco oculta su interés por el filósofo austriaco:

Wittgenstein, que hoy es centro de múltiples reflexiones, era obviamente una figura muy destacada cuando estaba escribiendo Respiración artificial. A mí me capturó muchísimo el grado de intensidad artística de la figura de Wittgenstein. Eso fue lo que me fascinó, el destino que este hombre había sido capaz de asumir, la intensidad dramática de su experiencia; me parecía excesivo ponerlo como centro de una novela, y quizá estaba equivocado. Lo que hice, entonces, fue inventar una especie de pseudo Wittgenstein, que fue Tardewski, una combinación de Gombrowicz con Wittgenstein (Pellegrini et al. 2010.).

El personaje de Respiración artificial fusiona en sí estas dos personalidades, soldadas sin fisuras al ser una semejante a la otra en muchos aspectos. Ambos fueron reticentes a reconocer abiertamente su homosexualidad, ambos sufrieron una especie de degradación económica (bastante más espectacular, es cierto, en el caso de Wittgenstein, oriundo de una de las más pudientes familias austriacas), a los dos la guerra les impuso el exilio que recrudeció su ya marcada misantropía. Finalmente, ambos conocieron el éxito que solo les trajo disgustos. "Era un hombre de genio, si es que eso existe-dice Tardewski sobre Wittgenstein, pero también serían acertadas sus palabras con respecto a Gombrowicz-pero en su vida fue desdichado como pocos y vivió atormentado hasta su muerte. Atormentado por sus ideas, no por otra cosa" (Piglia 2007, 165). A Piglia le interesa en ambos su capacidad de "llegar a extremos" (Pellegrini et al. 2010), desde los que-bordeando la locura-se percibe la realidad en una manera más clara y distinta que Descartes. 
En Respiración artificial, la impronta wittgensteiniana más recurrente es el silencio que pesa sobre los personajes: la famosa frase final de Tractatus es, de hecho, fielmente citada por Tardewski. Igualmente reveladoras, en el contexto de la novela, resultan las palabras que Wittgenstein dirigió a uno de los editores de su primer libro, explicándole que este consta de dos partes-la escrita y la silenciadade las cuales la segunda, dotada de un mensaje ético, es la más importante (véase Wolniewicz 2004, VIII). Contrariamente a la manera en que los neopositivistas abordaban los trabajos de Wittgenstein, el silencio tapa aquí no las cuestiones carentes de sentido - o sea, inexpresables en una frase correcta desde el punto de vista lógico-sino los problemas de importancia fundamental, los únicos que realmente valen la pena. La dialéctica de lo dicho y lo disimulado es cercana a Piglia, tanto en la dimensión formal- "lo más importante nunca se cuenta" (Piglia 2001, 108), dice sobre la construcción del texto literario-como en el contenido que, en el caso de Respiración artificial, también tiene una dimensión ética. La acción se reduce al diálogo, pero lo esencial se calla: "como usted ha comprendido, dice ahora Tardewski, si hemos hablado tanto, si hemos hablado toda la noche, fue para no hablar, o sea, para no decir nada sobre él, sobre el profesor. Hemos hablado y hablado porque sobre él no hay nada que se pueda decir" (Piglia 2007, 215).

¿Qué es lo que representa Tarewski en la novela? Para empezar, la tantas veces mencionada "perspectiva exterior": desde el lugar periférico que ocupa puede experimentar la famosa ostranenie, "la mirada del turista, pero también, en última instancia, la mirada del filósofo" (Piglia 2007, 156). Despojado de su lengua y, por tanto, incapaz de expresarse- - "es difícil decir la verdad cuando se ha abandonado la lengua materna", "una de las primeras cosas que se pierde al cambiar de idioma es la capacidad de describir" (Piglia 2007, 107)—nada más llegar, percibe lo absurdo de su condición: en uno de los periódicos bonaerenses, publica un texto que ni siquiera puede leer, porque desconoce el castellano. Habiéndolo perdido todo"en ese estado de absoluta desposesión, exiliado, con mi patria borrada del mapa, sin dinero, sin lengua propia, sin futuro, sin amigos, sin ropa que ponerme al otro día" (Piglia 2007, 189)-, intenta por lo menos asegurarse la propiedad de un descubrimiento propio, pero fracasa simbólicamente: su apellido se publicó con errata. Recuerda, en este aspecto, al Ricardo Piglia del cuento "Homenaje a Roberto Arlt" que, asimismo obsesionado con obtener la exclusividad de un hallazgo, termina frustrado: el supuesto texto inédito de Arlt resulta ser plagio de un escritor ruso. En ambos casos, el ansia de poseer un texto o una idea queda ridiculizada como una estéril ambición de gloria, una búsqueda de apreciación a ojos de otros "peones" de la literatura. Esta imposibilidad de poseer-de captar y fijar una interpretación—queda incrustada en la estructura misma de Respiración artificial, una novela hecha de citas: los personajes hablan con palabras de Joyce, Kafka o Borges, y con tesón se citan unos a otros, acudiendo a fórmulas de tipo "decía Marcelo, dice Renzi". Los pasajes sacados de obras canónicas y disimulados en el texto-nunca se informa de su procedencia—no sirven para corroborar las tesis que se defiende, fundarlas en una autoridad, ya que quedan "degradados" a nivel de las palabras de los protagonistas, funcionan sin privilegios y, a fin de cuentas, sólo proponen nuevos modelos de asociación: leer a Borges desde Arlt, a Gombrowicz desde Piglia, a Wittgenstein y Gombrowicz juntos. 
Resumiendo, Tardewski desciende sobre todo del último Gombrowicz, el que, poco antes de morir, dicta en Vence su Curso de filosofía en seis horas y cuarto. Pese a la fama que ya para entonces hasta le sobra, se siente un fracasado: el dolor no lo suelta y la filosofía lo rescata del suicidio. " ¿Qué hacer?-se interroga Tardewski tras sufrir en Argentina una desgracia total-Pregunta peligrosa. Por de pronto pensar: único modo conocido por mí de no volverme loco. Seguir una dirección de pensamiento lógica y coherente" (Piglia 2007, 183). El segundo Wittgenstein también afirmaba, despertando con ello el sincero disgusto de sus colegas neopositivistas, que su filosofía tiene básicamente un papel terapéutico: no le deja volverse loco. En el Curso, no se menciona, es cierto, al autor de Tractatus; en cambio se escriben estas elocuentes palabras sobre Descartes: "tuvo miedo de las consecuencias terroríficas de sus ideas" (Gombrowicz 2001, 26), asemejándose su angustia a la de los existencialistas. Gombrowicz está pensando en el horror del solipsismo, pero en el contexto de Respiración artificial este pasaje cobra nuevos sentidos: el racionalismo, entendido como un avance permanente del intelecto, supuestamente iba a acabar con la angustia humana, mientras que, en realidad, sólo desembocó en una barbarie antes deconocida.

Para concluir, ¿cuál sería la última apuesta de la "operación Gombrowicz" llevada a cabo por Piglia? No lo sería la demostración de las influencias del polaco en Borges y Arlt que, evidentemente, no existieron. Tampoco lo sería su asentamiento en la tradición rioplatense: los argumentos en favor de la argentinidad del autor de Ferdydurke se dan de paso y a sabiendas de que Gombrowicz, a fin de cuentas, no era Conrad. La última apuesta, como ha quedado dicho al principio del presente artículo, es, pues, Piglia mismo, su propio lugar en las letras argentinas. Contrariamente a los autores como Saer o-_para qué ir más lejos?-Gombrowicz, que fijan su posición en la literatura afirmando su propia excepcionalidad, delimitando su espacio, el autor de Respiración artificial prefiere posicionarse como lector (traductor, comentador, prologuista, etc.), enfatizando de este modo su aparente dependencia de los demás (Premat 2009, 203-236). Dime a quién lees y te diré cómo eres: de ahí la importancia de inventar parentescos. Así, las categorías tales como el rechazo por parte del establishment o la academia, el uso irrespetuoso e innovador de la lengua, la tendencia a autoinventarse desafiando a otros autores y, finalmente, el planteamiento de interpretaciones desviadas (leer a Gombrowicz desde Wittgenstein) son las que se aplican, en fin, a la crítica y ficción piglianas.

Open Access This article is distributed under the terms of the Creative Commons Attribution License which permits any use, distribution, and reproduction in any medium, provided the original author(s) and the source are credited.

\footnotetext{
9 La base del Curso la constituyó el libro de Manuel García Morente, Lecciones preliminares de filosofía, para Gombrowicz, un libro de cabecera en Vence (Gombrowicz 2002, 340). Curiosamente, el filósofo español no goza de la misma estima a ojos de Tardewski, que habiendo deformado con desdén su apellido, lo llama "un tipo de ignorancia casi genial" (Piglia 2007, 168).
} 


\section{References}

Abos, Á. (1991). El cuarteto de Buenos Aires. Quimera. Revista de literatura, 101, 12-19.

Arlt, R. (1995). Escritor fracasado. In D.-L. Hernández (Ed.), Roberto Arlt. Narrativa corta completa (Vol. 1, pp. 37-63). La Laguna: Universidad de la Laguna.

Blanco Calderón, R. (2008). Piglia y Gombrowicz: sobre el fracaso y otras estrategias de escritura. In J. Carrión (Ed.), El lugar de Piglia. Crítica sin ficción (pp. 27-43). Barcelona: Candaya.

Borges, J. L. (2005). El escritor argentino y la tradición. In Obras Completas (Vol. 1, pp. 267-274). Barcelona: RBA.

Drucaroff, E. (1998). Arlt. Profeta del miedo. Buenos Aires: Catálogos.

Espejo, M. (2004). Gombrowicz y la Argentina, en el centenario de su nacimiento. Cuadernos hispanoamericanos, 648, 95-100.

Fornet, J. (2000a). Conversación con Ricardo Piglia. In J. Fornet (Ed.), Ricardo Piglia (pp. 17-44). Bogotá: Casa de las Américas.

Fornet, J. (2000b). Un débate de poéticas: las narraciones de Ricardo Piglia. In E. Drucaroff (Ed.), Historia critica de la literatura argentina (Vol. 11, pp. 345-360). Buenos Aires: Emecé.

Gasparini, P. (2007). El exilio procaz: Gombrowicz por la Argentina. Rosario: Beatriz Viterbo Editora. Goloboff, M. (2002). Roberto Arlt: la máquina literaria. Revista de Literaturas Modernas, 32, 107-115. Gombrowicz, W. (2001). Curso de filosofía en seis horas y cuarto. Barcelona: Tusquets.

Gombrowicz, R. (2002). Gombrowicz w Europie. 1963-1969. Kraków: Wydawnictwo Literackie.

Gombrowicz, W. (2004). Testament. Rozmowy z Dominique de Roux. Kraków: Wydawnictwo Literackie.

Gombrowicz, R. (2005). Gombrowicz w Argentynie. Kraków: Wydawnictwo Literackie.

Gombrowicz, W. (2009). Contra los poetas. Madrid: Sequitur.

Gombrowicz, W. (2011). Diario (1953-1969). Barcelona: Seix Barral.

Grzegorczyk, M. (1996). Discursos desde el margen: Gombrowicz, Piglia y la estética del basurero. Hispamérica. Revista de literatura, 73, 15-34.

Jarzębski, J. (2000). Podgladanie Gombrowicza. Kraków: Wydawnictwo Literackie.

Kalicki, R. (1984). Tango Gombrowicz. Kraków: Wydawnictwo Literackie.

Mandolessi, S. (2007). Heterotopía y literatura nacional en Diario argentino de Witold Gombrowicz. Ciberletras, 18, 1-15.

Mandolessi, S. (2008). Cultural hierarchies, secondary nations: the tension between Europe and "minor" cultures in Witold Gombrowicz and Jorge Luis Borges. In N. Bemong, M. Truwant, \& P. Vermeulen (Eds.), Re-thinking Europe: Literature and (trans)national identity (pp. 151-162). Amsterdam: Rodopi.

Matamoro, B. (1989). La Argentina de Gombrowicz. Cuadernos hispanoamericanos, 469-470, 271-279.

Montesano, G. (2009). Elogio de Witold Gombrowicz. Quimera. Revista de literatura, 313, 77-81.

Pellegrini, M., Monder, S., \& Jeftanovic, A. (2010). Conversación con Ricardo Piglia. http://letras.s5. com/mp010810.html. Consultado el 16 Mar 2012.

Piglia, R. (2001). La novela polaca. In Formas breves (pp. 68-80). Barcelona: Anagrama.

Piglia, R. (2006). Crítica y ficción. Buenos Aires: Anagrama.

Piglia, R. (2007). Respiración artificial. Buenos Aires: Anagrama.

Piglia, R. (2008a). El lugar de Saer. In J. Carrión (Ed.), El lugar de Piglia. Crítica sin ficción (pp. 162-188). Barcelona: Candaya.

Piglia, R. (2008b). La lengua de los desposeídos. La Nación 19.04. http://www.lanacion.com.ar/10045 90-la-lengua-de-los-desposeidos. Consultado el 16 Jan 2012.

Premat, J. (2009). Héroes sin atributos. Figuras de autor en la literatura argentina. Buenos Aires: Fondo de Cultura Económica de Argentina.

Rodak, P. (2011). Między zapisem a literatura. Warszawa: WUW.

Saer, J. J. (2004). La perspectiva exterior: Gombrowicz en la Argentina. In El concepto de ficción (pp. 17-29). Barcelona: Seix Barral.

Saítta, S. (2008). El escritor en el bosque de ladrillos. Una biografía de Roberto Arlt. Buenos Aires: Debolsillo.

Suchanow, K. (2005). Argentyńskie przygody Gombrowicza. Kraków: Wydawnictwo Literackie.

Wolniewicz, B. (2004). Wstęp. O Traktacie. In L. Wittgenstein (Ed.), Tractatus logico-philosophicus (pp. VII-XLII). Warszawa: PWN. 